\title{
A study of inter-relationship between prolonged breast feeding and nutritional status in children aged 15 months to 3 years: An observational, case-control study
}

\author{
*Syed Muneeb Ur Rehman Qadri ${ }^{1}$, Hubaira ${ }^{1}$, Deepti Singh ${ }^{2}$
}

Sri Lanka Journal of Child Health, 2017; 46(4): 362-365

\begin{abstract}
Background: The advantages of exclusive breastfeeding (BF) in the first 6 months of life with complementary feeding afterwards is well established but till when should BF be continued has long been a matter of debate.
\end{abstract}

Objectives: To study the inter-relationship between prolonged $\mathrm{BF}$ (beyond 1 year of age) and nutritional status in terms of wasting and stunting in children from 15 months to 3 years of age.

Method: This case-control study included 350 children aged 15 to 36 months belonging to the lower socioeconomic class visiting the free outpatient department (OPD) of Batra Hospital \& Medical Research Centre, 250 children with BF for more than 12 months as cases and 100 children $\mathrm{BF}$ for one year or less as controls. Socio-demographic factors like parents' educational status and occupation, family type and family size were taken. Child characteristics like age, sex, recent illness, past illness, birth order and current feeding status were taken and recorded on a pre-coded and pre-tested proforma. Weight and height/length were taken as nutritional parameters and classified as wasting, stunting and underweight as per World Health Organisation (WHO) growth charts. Statistical analysis was performed using SPSS version 17. The clinical profile and nutritional status was analysed by Chi-square test for qualitative variables and student t-test for quantitative variables. Correlation between the duration of $\mathrm{BF}$ and nutritional status was done by Spearman/Pearson correlation test. Confounding factors were assessed in linear regression analysis.

\footnotetext{
${ }^{1}$ Shaheed Hassan Khan Mewati Government Medical College, Mewat, India, ${ }^{2}$ Senior Consultant, Batra Hospital, New Delhi, India

*Correspondence: d.smurq@gmail.com

(Received on 23 March 2017: Accepted after revision on 19 May 2017)
}

The authors declare that there are no conflicts of interest

Personal funding was used for the project.

Open Access Article published under the Creative

Commons Attribution CC-BY License
Results: The nutritional status as per the anthropometric indices studied for (height/length for age, weight for height/length, weight for age) was found to have no statistically significant difference between the two groups. The prevalence of malnutrition as per the anthropometric indices studied was found to be quite high but comparable to the NFHS-3 data for India and the UNICEF-WHO data for South Asia.

Conclusion: There was no inter-relationship between the prolonged $\mathrm{BF}$ and the nutritional status of the children aged 15 to 36 months.

DOI: http://dx.doi.org/10.4038/sljch.v46i4.8385

(Keywords: Prolonged breast feeding, complementary feeding, wasting, stunting, WHO growth charts)

\section{Introduction:}

The advantages of breastfeeding (BF) are undoubtedly considerable, but by itself, breast milk is insufficient to meet the rising nutritional needs and declining stores of the rapidly growing infants after a certain age after which it forms a decreasing but valuable supplementary source of complete protein, fat, calcium and vitamins ${ }^{1}$. At present there is a near unanimity that exclusive $\mathrm{BF}$ is sufficient for nutritional requirement till 6 months of age ${ }^{1,2}$. However, the duration till which the BF should be continued has been a point of considerable debate with the World Health Organisation (WHO) and the Indian Academy of Paediatrics (IAP) currently recommending it till 2 years of life or beyond ${ }^{2}$. Some authors maintain that prolonged BF may adversely affect a child's nutritional status, even when adequate supplementary foods ${ }^{3}$ are provided, by affecting the child's acceptance of these supplements or by disturbing the regulation of appetite $^{4}$. The suggestion that BF may be detrimental to the child has provoked strong and sometimes hostile responses ${ }^{5,6}$. Some other studies showed no significant association between prolonged $\mathrm{BF}$ and malnutrition ${ }^{7,8}$. Certain others even showed a positive association ${ }^{9,10,11}$. However, it is possible that the apparent increase in malnutrition among prolonged breastfed children may be due to an inadequate complementary feeding or confounding variables like the age of the 
child $^{12,13}$, sex ${ }^{13,14}$, birth-order, socio-economic ${ }^{15}$, demographic and cultural characteristics of the community ${ }^{16}$. Thus, this study was designed as an observational case-control study, taking the prolonged BF children (breastfed for more than 1 year) as cases and those breastfed for less than 1 year as controls, to compare the nutritional status between them. And also to study and compare the other confounding factors like maternal occupation, maternal educational status, family type, family size, birth order, top-feeding and complementary feeding between the two groups so as to evaluate the inter-relationship between prolonged breast feeding and nutritional status in the children aged 15 months to 36 months, belonging to the lower socio-economic group visiting the free OPD of our hospital.

\section{Objectives}

To study the inter-relationship between prolonged breastfeeding (breastfeeding beyond 1 year of age) and nutritional status in terms of wasting and stunting in children aged between 15 months to 3 years.

\section{Method}

It is a case-control study taking the prolonged breast-fed children (breast-fed for more than 1 year) as cases and non-prolonged breast fed children (breast fed for less than 1 year) as controls. The study was done in the Batra Hospital and Medical Research Centre, New Delhi for a period of one year. Only the children belonging to the lower socio-economic group were taken from among those visiting the free outpatient department (OPD) for general check-up or minor ailments, excluding those who were found to be seriously ill or suffering from any chronic disease. A total of 250 cases as against 100 controls were taken. The sample size was calculated properly at $95 \%$ confidence level and taking the prevalence of prolonged $\mathrm{BF}$ in our country as $50 \%$ and with a relative error of $20 \%$ calculating which the minimum sample size came out to be 225 for cases.

The two groups were studied and compared for various socio-demographic, maternal and child characteristics namely, family type, family size, fathers' educational status, fathers' occupational status, mothers' educational status, mothers' occupational status, birth order of the index children and current feeding status (top-feeding, complimentary feeding). The nutritional status was described as per the various anthropometric indices namely, height/length for age, weight for age and weight for height/length. The assessment was done as per the WHO charts for international reference. Malnutrition was defined as per the different anthropometric indices namely stunting (height/length for age $<\mathrm{SD}$-2), wasting (weight for height/length) and underweight (weight for age $<$ SD -2).

The statistical analysis was done using SSPS version 17 . The various variables were analysed by Chi-square test for qualitative variables and student t-test for quantitative variables. Correlation between the duration of breastfeeding was done by Spearman/Pearson correlation test. Confounding factors were assessed in linear regression analysis.

\section{Results}

\section{Socio-demographic factors}

Sex: Of the 250 cases, 134 (53.6\%) were boys and $116(46.4 \%)$ were girls. Of the 100 controls, 63 $(63 \%)$ were male and $37(37 \%)$ were female.

Mothers' educational status: The literacy rate among mothers was $52.8 \%$ in the cases group as against $45 \%$ in the control group. The difference was statistically insignificant $(p=0.195)$.

Mothers' occupation: In the cases group, 209 $(83.6 \%)$ mothers were housewives. $6.4 \%$ were working in the private companies mostly on daily wages, $4.0 \%$ were labourers, $3.6 \%$ were working as domestic help in the neighborhood households (maids) and $2.4 \%$ were self-employed in small scale shops, retail outlets etc. Among the control group $49 \%$ were housewives, $19 \%$ worked in the private sector, $16 \%$ as domestic help, $11 \%$ were labourers, $4 \%$ were self-employed and $1 \%$ had government jobs. The difference between the two groups was statistically significant $(p<0.001)$.

Top-feeding: Among the cases $94 \%$ children were receiving top-feeding, $67.6 \%$ using cow's milk, $22 \%$ using buffalo's milk, $7 \%$ using formula feeds and $4 \%$ using goat's milk. Among the controls $91 \%$ children were receiving top- feeding, $73 \%$ using cow's milk, 15\% using buffalo's milk, 2\% using goat's milk and $1 \%$ using formula feeds. The $p$ value of the cross analysis was 0.397 , which is statistically insignificant.

Complementary feeding: Among the cases 107 $(42.8 \%)$ were receiving adequate complementary feeds. Among controls 40\% were getting adequate complementary feeds. The difference was insignificant $(p=0.361)$.

Time of starting complementary feeding: Among the cases, complementary feeds in the form of semisolid/ solid, household feeds were started in $0.8 \%$ at 4 months of age, $11.6 \%$ at 5 months, $58 \%$ at 6 months, $14 \%$ at 7 months, $10 \%$ at 8 months, $2.8 \%$ at 9 months and $2.8 \%$ at 10 months or beyond. Among the controls, complementary feeds were started in $10 \%$ at 5 months, $57 \%$ started at 6 months, $12 \%$ at 7 months, $17 \%$ at 8 months, $1 \%$ at 9 months and $3 \%$ at 10 months or beyond. No significance difference was seen statistically $(p=$ $0.585)$. 
Nutritional Status:

Height/length for age:

Of the 250 cases, $115(46 \%)$ were found to be less than 2 standard deviations $(<2 \mathrm{SD})$ from the mean, $41(16.4 \%)$ being less than 3SD from the mean. Among the 100 controls $48 \%$ were less than 2SD from the mean, $18 \%$ being less than $3 \mathrm{SD}$ from the mean. The difference between the two groups was statistically insignificant $(\mathrm{p}=0.141)$.

Weight for height/ length:

Of the 250 cases, $57(22.8 \%)$ were found to be less than 2SD from the mean, $9(3.6 \%)$ being less than $3 \mathrm{SD}$ from the mean. Among the 100 controls $24 \%$ were less than 2SD from the mean, 3\% being less than 3SD from the mean. The difference between the two groups was statistically insignificant $(\mathrm{p}=$ $0.594)$.

Weight for age:

Of the 250 cases, $129(51.6 \%)$ were found to be less than 2SD from the mean, $45(18.0 \%)$ being less than 3SD from the mean. Among the 100 controls $52 \%$ were less than $2 \mathrm{SD}$ from the mean, $21 \%$ being less than 3SD from the mean. The difference between the two groups was statistically insignificant $(p=0.234)$

The results remained same after assessing the various confounders observed in the regression analysis, concluding that there was no significant association between the prolonged breastfeeding and the nutritional status of the children.

\section{Discussion}

The duration till which the breastfeeding should be continued, beyond the initial 6 months of life, has been a point of considerable debate for long. Cousens et $\mathrm{al}^{7}$ in their study found that in 152 case-control pairs in which both children were receiving solid foods, non-breast-feeding was associated with an increased risk of clinical malnutrition. Rao S, Kanade $\mathrm{AN}^{14}$ in their study found that there was no evidence of any protective benefit of partial breast-feeding beyond infancy. Kathleen M. Buckley ${ }^{8}$ also reported similar findings in children receiving partial breast feeding aged 12 to 43 months. However, Caulfield LE et $\mathrm{al}^{12}$ indicated in his study that the children continuing breastfeeding for longer duration were shorter and lighter than those who were no longer breast-fed at the time of study.

Wafaie W Fawzi et $\mathrm{al}^{17}$ came up with a newer concept of reverse causality. They found the inverse association between breastfeeding status and weight gain was significantly larger among children of poor or illiterate mothers compared with children of relatively more affluent or literate mothers thus demonstrating that undernourished children were more likely to be breastfed for a longer period of time compared with normal children. This was further supported by K.B. Simondon et $\mathrm{al}^{18}$ observing that women prolonged breastfeeding for undernourished children and reduced the duration for well-nourished children, probably because they of their belief of increased mortality risk following weaning.

In our study, there was no significant difference between the various confounding factors in the two groups and the nutritional status of the two groups was also more or less similar. The result of our study hence supports the earlier reasoning that there are no clear nutritional reasons to suggest that prolonged breast feeding should lead to malnutrition. No statistically significant difference was found to be present between the two groups in the various factors studied except for the maternal occupation status. It was found that among the factors studied only the maternal occupation had a significant role determining the duration of breast feeding (more than 1 year or less than 1 year). The complementary feeding was found to be predominantly inadequate in both groups, but no statistically significant difference was observed between the two.

\section{References}

1. Kramer MS, Kakuma R. Optimal duration of exclusive breastfeeding. Available from:

http://www.cochrane.org/CD003517/PRE

G_optimal-duration-of-exclusive-breastfee ding

2. Infant and Young Child Feeding Guidelines: 2010. Indian Pediatrics 2010; 47; 995-1004.

PMid: 21220795

3. Brakohiapa LA, Bille A, Quansah E, Kishi $\mathrm{K}$, Yartey J, Harrison $\mathrm{E}$ et al. Does prolonged breast feeding adversely affect a child's nutritional status? The Lancet 1988; 2(8608): 416-8.

https://doi.org/10.1016/S0140-6736(88)90 411-4

4. Michaelsen KF. Value of prolonged feeding (Letter). Lancet 1988; 2(8614):788-9.

5. Rohde JE. Breastfeeding beyond twelve months. Lancet 1988; 2(8618): 1016.

6. Prentice, A. Breast feeding and the older infant. Acta paediatrica Scandinavica (suppl.) 1991; 374: 78-88. 
7. Cousens $\mathrm{S}$, Nacro $\mathrm{B}$, Curtis $\mathrm{V}$, et al. Prolonged breast-feeding: no association with increased risk of clinical malnutrition in young children in Burkina Faso. Bulletin of the World Health Organisation 1993; 71(6): 713-22.

PMid: 8313489 PMCid: PMC2393530

8. Buckley KM. Long-term breastfeeding: Nourishment or nurturance? J Hum Lact 2001; 17(4) 304-12.

https://doi.org/10.1177/089033440101700 404

PMid: 11847899

9. Taren D, Chen J. A positive association between extended breast-feeding and nutritional status in rural Hubei Province, People's Republic of China. American Journal of Clinical Nutrition 1993; 58(6); 862-7.

PMid: 8249868

10. Khatoon T, Mollah MAH, Choudhury AM, Islam MM, Rahman KM. Association between infant- and child-feeding index and nutritional status: results from a cross-sectional study among children attending an urban hospital in Bangladesh. Journal of Health, Population, and Nutrition 2011; 29(4): 349-56.

https://doi.org/10.3329/jhpn.v29i4.8450

11. Onyango AW, Esrey SA, Kramer MS. Continued breastfeeding and child growth in the second year of life: a prospective cohort study in western Kenya. Lancet 1999; 354(9195):2041-5. https://doi.org/10.1016/S0140-6736(99)02 168-6

12. Caulfield LE, Bentley ME, Ahmed S. Is prolonged breastfeeding associated with malnutrition? Evidence from nineteen demographic and health surveys. International Journal of Epidemiology 1996; 25: 693-703.

https://doi.org/10.1093/ije/25.4.693

PMid: 8921445
13. Adair L, Popkin BM, VanDerslice J, Akin $\mathrm{J}$ et al. Growth dynamics during the first two years of life: a prospective study in the Philippines. European Journal of Clinical Nutrition 1993; 47(1):42-51. PMid: 8422872

14. Rao S, Kanade AN. Prolonged breast-feeding and malnutrition among rural Indian children below 3 years of age. European Journal of Clinical Nutrition 1992; 46(3):187-95.

PMid: 1559523

15. Rao S, Rajpathak V. Breastfeeding and weaning practices in relation to nutritional status of infants. Indian Pediatrics 1992; 29(12):1533-9.

PMid: 1291499

16. Martin RM. Commentary: Does breastfeeding for longer cause children to be shorter. International Journal of Epidemiology 2001; 30(3); 481-4. https://doi.org/10.1093/ije/30.3.481 PMid: 11416069

17. Fawzi WW, Herrera MG, Nestel P, El Aminc A, Mohamed KA. A longitudinal study of prolonged breastfeeding in relation to child undernutrition. International Journal of Epidemiology 1998: 27: 255-260

https://doi.org/10.1093/ije/27.2.255

PMid: 9602407

18. Kirsten B Simondon, Francois Simondon. Mothers prolong breastfeeding of undernourished children in rural Senegal. International Journal of Epidemiology 1998; 27: 490-4.

https://doi.org/10.1093/ije/27.3.490 